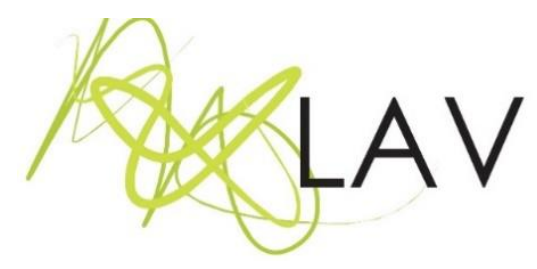

\title{
Poéticas Visuais em Arte-Educação: Video-Encruzilhada
}

\author{
Visual Poetics in Art-Education: Video-Crossroad
}

Maria Cristina Mendes ${ }^{i}$ Universidade Estadual de Ponta Grossa

\begin{abstract}
Resumo
Vídeo-Encruzilhada (2:53min, 2016) se apropria de um trabalho anônimo encontrado em uma ciclovia e problematiza o lugar da Arte na contemporaneidade. O objetivo principal da pesquisa é correlacionar o vídeo a uma reflexão sobre sua criação, considerando as singularidades das imagens apropriadas. Os objetivos secundários são: estabelecer uma trama de possíveis sentidos para o trabalho e verificar as dificuldades encontradas na execução do projeto. O vídeo se relaciona ao Caminhando de Lygia Clark, obra fundamental para a experiência da fruição estética na educação do sensível. A ideia de encruzilhada como lugar de troca tem bases nos estudos sobre Leminski; a pesquisa sobre poéticas visuais se estrutura em Tessler e Fervenza; e a relação entre Arte e Educação tem aporte nas contribuições de Read.
\end{abstract}

Palavras-chave: vídeo-encruzilhada, poéticas visuais, arte-educação.

\begin{abstract}
Video-Encruzilhada (2:53 $\mathrm{min}, 2016)$ appropriates an anonymous work of art found on a bike lane and problematizes the role of art in contemporaneity. The main objective of the research is to correlate the video with a reflection about its creation, considering the singularities of the appropriated images. The secondary objectives are to establish a network of possible meanings for the work and to verify the difficulties found in the project execution. The video relates to Caminhando by Lygia Clark, a fundamental work for the experience of aesthetic fruition in the education for the sensible. The idea of a crossroad as a place for exchanging is based upon investigations on Leminski's work; the research on visual poetics is anchored in Tessler's and Fervenza's researches; and the relation between Art and Education is structured in Read's contributions.
\end{abstract}

Keywords: video-crossroad, visual poetics, art-education. 
"Troncotocado raio, miringuada água pulcra. Exumam catapataratas na encruzilhada, resumam a trilha estrelhada"

(Paulo Leminski)

\section{Introdução}

A pesquisa em Artes Visuais tem recebido maior atenção acadêmica nas últimas décadas e os esforços para explicitar os processos de realização de uma obra se tornam cada vez mais significativos. No entanto, existem ainda artistas que preferem não falar sobre seu trabalho, afirmando que a Arte deve gerar sentido por sua própria presença e que o depoimento de quem a realizou pode atrapalhar a fruição estética. Guardado o devido respeito a tal atitude, este artigo tem por meta tratar algumas questões referentes aos processos poéticos, em sua capacidade de fundamentação da atividade criativa. Tais processos investigativos são fundamentais para os cursos superiores de Arte onde se procura desenvolver com maior intensidade e profundidade a pesquisa em poéticas visuais.

É nas Universidades que orientadores incentivam estudantes a desenvolver seus próprios métodos de pesquisa em Arte, considerando a individualidade das necessidades expressivas e as possibilidades de diálogo no que se refere à produção contemporânea. Ao estabelecer relações dialógicas com outras obras, em intrincados processos de subjetivação e objetivação, costumam ser adotados processos interdisciplinares, numa evidência da integração da Arte com a vida.

Este artigo tem por meta analisar o trabalho Vídeo-Encruzilhada, realizado por mim e por Pedro Prosdócimo Neto no ano de 2016. Pontuo a distância entre a concepção e a concretização da obra, ou seja, entre a ideia e o produto. Coloco em pauta possíveis referências históricas e indico algumas chaves de leitura. Enfatizo o caráter polissêmico da Arte, lembrando que a inesgotabilidade de sentidos é uma das características da fruição estética. Procuro, também, evidenciar o valor de um repertório amplo e interdisciplinar para o campo da pesquisa em Artes Visuais, em seu constante diálogo com a sociedade.

Longe de delimitar questões acerca da produção artística, procuro, a exemplo da análise sobre meu próprio trabalho, abrir caminho para novas investigações, evidenciando que as reflexões tecidas sobre as obras, criam uma espécie de rede de informações a nutrir a experiência estética. De modo diverso de uma leitura da obra pronta, a investigação poética busca levantar questões sobre os processos que dão origem à obra, ou sobre o projeto da obra, numa observação da diferença que existe entre a concepção e sua materialização. 
Considero, ainda, que a educação pelo sensível é uma das maneiras de reverter os processos de anestesia gerados pelo consumo capitalista, ampliando o valor de aspectos mais delicados da existência. Na contramão da competitividade e da necessidade de vencer a qualquer custo, os caminhos da Arte apresentam sutilezas que merecem ser identificadas, pois quando se busca trabalhar com o sensível, as relações tendem a se tornar mais humanas e respeitosas.

\section{Educação pelo sensível}

Preocupo-me quando tento fazer com que jovens universitários, com idades que se aproximam dos vinte anos, compreendam que ninguém sabe muito bem explicar o que é Arte Contemporânea. Conto que existem parâmetros norteadores, tais como as grandes feiras e algumas exposições, a palavra de curadores ou o aval das instituições oficiais. Enfatizo também que o conhecimento da História da Arte e da cena cultural é importante. Pouco disso, contudo, tem a ver com a experiência que se depreende da obra de Arte, com a fruição estética ou com o prazer que vai se educando, gradativamente, para a percepção de qualidades sutis na vida cotidiana. A formação de professores de Arte, tarefa que exige constante questionamento das diretrizes curriculares, é um ofício que tem como pressuposto formar agentes de humanização e de sensibilização no universo escolar.

Os conceitos de Arte e os modos de se ensinar Arte no século XXI são atravessados pelo excesso de informação das redes midiáticas, por onde circulam, tanto dados valorosos quanto equivocados. Compreender uma produção mais hermética como a que acontece desde o início do século XX costuma requerer tempo e dedicação, elementos cada vez mais raros nas esferas das sociedades de consumo. Acima de tudo, insiste-se em estabelecer uma definição do que é Arte, justificando a compreensão da obra por vias da razão e não por meio da percepção sensível. Diante do senso comum ou da determinação política, resta pouco espaço para o prazer desinteressado, ou para investigações acerca deste mesmo prazer.

As pesquisas em Arte-Educação apontam para a necessidade de ampliar o debate para questões mais abrangentes da cultura, enfatizando o investimento em processos de sensibilização dos estudantes. Mesmo que não se ambicione criar, fora do âmbito universitário, classes de ou para alunos/artistas, é importante considerar que, dentre os estudantes, pode-se encontrar alguém cuja vida será dirigida por caminhos do sensível. De acordo com Herbert Read, um dos consagrados pensadores da Arte, as Belas-Artes "representam a cultura em seu estágio mais coerente; e uma obra de Arte incorpora os valores dessa cultura com a maior vividez possível. Assim, o prazer da apreciação 
artística é a maneira mais valiosa de adquirirmos nossos hábitos de apreensão estética" (READ, 2013, p. 291).

Muito embora os escritos de Read possam parecer utópicos na atual conjuntura nacional, sua retomada é dadivosa, pois neles se encontram os necessários respaldos para possíveis debates dos envolvidos em Arte-Educação. Além dos problemas didáticopedagógicos enfrentados pelos docentes e devidamente explicitados pelo pesquisador inglês na década de 1940, outro desafio se apresenta para professores artistas, os quais ministram disciplinas de História da Arte, Desenho ou Pintura, sem deixar de dar continuidade à própria produção. Realizar um trabalho de Arte e criar um ambiente onde se possa discutir tal obra deveria ser uma das características dos cursos de Artes Visuais, pois é dentro de uma Universidade que as pesquisas científicas costumam ter o devido respeito e incentivo.

A artista Elida Tessler, afirma que uma das alternativas que resta aos artistas é o entrecruzamento de produção e reflexão, de prática e teoria. De acordo com a pesquisadora do Instituto de Artes da UFRGS, é nos cursos de Artes que "abrimos espaço para o não saber, regando os grãozinhos de desconfiança que ainda nos restam. Valorizamos a incerteza, em seu sentido salutar. Nossas dúvidas tornam-se matéria prima de nossas pesquisas" (TESSLER, 2002, p. 109 -110).

$\mathrm{Na}$ convicção de que a busca de equilíbrio entre informação e conhecimento sensível deveria ser o elemento formador das novas gerações, a Arte-Educação é o elemento capaz de estabelecer critérios de valores estéticos e éticos, adequados para promover uma efetiva transformação na qualidade da vida. Na contemporaneidade, quando competitividade e sucesso midiático assumem o lugar do conhecimento, a Arte se encontra em sucessivas encruzilhadas: inútil para uma abordagem pragmática da subsistência, fundamental para a qualidade desta mesma existência. Por sua proximidade ou parentesco com o filosófico e com o imaterial, é o campo da Arte que cede espaço para a presença do imaginário, onde as percepções costumam ser desenvolvidas e educadas.

\section{Poética, metodologia e apropriação}

A discussão sobre poéticas visuais, com bases em Aristóteles e Paul Valery ${ }^{1}$, tem encontrado nas Universidades brasileiras um campo fecundo para discussões. A singularidade de tais discussões reside no fato de que elas partem do questionamento das metodologias usualmente adotadas, já que as pesquisas científicas em outras áreas,

${ }^{1}$ O texto que fundamenta as pesquisas atuais é de 1937, quando é criada, para Valery, a Cadeira de Poéticas na Sorbonne.

Revista Digital do LAV - Santa Maria - vol. 11, n. 3, p. 4 - 19 - set./dez. 2018 ISSN 1983 - 7348 http://dx.doi.org/10.5902/1983734832832276 
como as ciências exatas ou biológicas, têm bases em processos investigativos de diferente teor. Distintamente das análises quantitativas das demais ciências, cuja comprovação se dá mediante dados concretos, as pesquisas em Arte são permeadas pela subjetividade e pela educação do aspecto sensível do ser humano, dados que guardam em seu cerne a dificuldade de explicitação de seus próprios critérios de observação e apreciação.

As possibilidades de criação e de estabelecimento de metodologias de pesquisa em Arte são inúmeras e variam de acordo com os interesses de cada artista. Sobre esta espécie de proliferação das possibilidades investigativas no campo das Artes, Helio Fervenza, também professor pesquisador do Instituto de Artes da UFRGS, esclarece:

Os caminhos são muitos e, apesar de darmos indicações para percorrê-los, são também muito difíceis. São inevitáveis as bifurcações, os desvios, as pontes, as derivas do andar. Muitas vezes jogamos pedras no escuro, para que estas nos indiquem a presença ou a ausência dos abismos. O caminho está indissoluvelmente ligado ao caminhante e a seu andar. Resumindo: os caminhos em questão se fazem à medida que caminhamos. Daí a dificuldade de traçá-los inteiramente a priori, sem que esse trajeto inicial não seja revisto, alterado, modificado a todo instante. Daí talvez sua impossibilidade mesmo (FERVENZA, 2002, p. 67).

Poética e metodologia acabam por se tornar muito próximas, e suas relações são fundamentais para a concretização da obra: sem poética não se coordenam ideias e sem metodologia não se consegue dar materialidade a tais ideias. Na Arte, os métodos investigativos e os processos de pesquisa costumam não ter uma receita pronta e na maior parte das vezes é o próprio pesquisador quem estabelece os parâmetros das verificações. O que se mantém como padrão nas pesquisas universitárias é a necessidade de, junto ao desenvolvimento do trabalho prático, apresentar um texto reflexivo, que não seja mera descrição da obra, mas que potencialize a variedade de sentidos provindos da fruição estética. Ao tentar coadunar razão e emoção, prática e teoria, os artistas/pesquisadores arriscam, duvidam, tecem provisórias conclusões, tendo como terreno seguro a História da Arte e o legado cultural da humanidade.

A história das imagens no mundo ocidental parece seguir em duas direções opostas, uma valoriza a verossimilhança e outra a necessidade expressiva interior. Para ambas, o parâmetro norteador, contra ou a favor, é a capacidade mimética da obra, ou seja: parecer com o real. O método de representar as três dimensões num plano bidimensional, organizado no Renascimento, até hoje exerce seu poder de convencimento visual, sendo que poucas pessoas, fora do âmbito dos estudos artísticos, 
se dão conta de que esta é uma criação humana. Mais de quinhentos anos depois, os dispositivos de registro e gravação de imagens ainda reproduzem o modelo renascentista, sendo que a fidelidade à imagem original e a capacidade de aumento da profundidade de foco são o mote de atenção das pesquisas tecnológicas vinculadas à produção de novos equipamentos.

A Arte Moderna, na primeira metade do século XX, busca a especificidade de cada uma de suas modalidades, procurando identificar a essência de cada expressão. Em outras épocas, contudo, o que impera é o anonimato e a produção coletiva. Distante da consagração do artista enquanto sujeito que instaura um novo saber, na Idade Média, retábulos e iluminuras são reproduzidos visando uma similaridade a um modelo; prescindem da originalidade e recontam, em boa parte das vezes, a mesma história. Não existe assinatura, e salvo raras exceções ou estudos aprofundados, não parece ser importante identificar o artista, conservando-se apenas o nome da escola ou do local de execução das obras.

Com a possibilidade de autoextermínio, ao final da Segunda Guerra Mundial, a humanidade se dá conta da falência do projeto modernista, com seu foco no constante avanço tecnológico, sem levar em conta a debilitação do planeta. Envolvidos numa espécie de ir sempre em frente, realizando novas conquistas, mais parecemos animais predadores do que seres humanos conscientes dos problemas sociais que assolam o planeta. Sob a égide do termo pós-moderno valoriza-se, a partir da década de 1980, o retorno ao passado, não por mero saudosismo, mas pela simples impossibilidade de seguir adiante.

Muito embora a nomenclatura "pós-moderno" tenha sido adotada nas Artes Visuais apenas por um breve período na década de 1980, a utilização do termo ainda pode ser encontrada na literatura e na sociologia. As práticas artísticas e sociais, dentro dos parâmetros pós-modernos, são perpassadas pela citação, pela retomada dos mitos, pelo medo do fim do mundo, pelo anonimato e pelas produções coletivas. Para William Dunning (1995), as raízes da pós-modernidade podem ser encontradas na Idade Média e embora o período mencionado seja demasiadamente abrangente, tanto no que concerne à duração temporal, quanto no que se refere à produção de Arte, é importante perceber que, ao pensar o tempo como algo cíclico e não linear, as demais categorias perceptivas também são transformadas.

As apropriações, portanto, passam a ser valorizadas na contemporaneidade, auxiliando na criação de camadas de sentido, as quais se revelam de acordo com o repertório de 
cada um. As redes de informação que transformam as relações humanas passam a veicular outro tipo de produção de Arte, a qual adota diversos tipos de referências, retiradas do campo da própria Arte ou estabelecidas através de relações interdisciplinares. Desejadas por trazerem uma espécie de arejamento para o universo artístico, as trocas informacionais contribuem para a efetivação de relações dialógicas e identificam interesses comuns. Problematizam, ainda mais, a definição do que é Arte e qual seu lugar nas sociedades do século XXI.

\section{Encruzilhadas de sentidos}

Há cerca de dois anos, ao caminhar na ciclovia do Alto da XV, em Curitiba, deparei-me com uma linha branca no asfalto, como se um pintor houvesse derrubado a tinta da lata enquanto andava. Alguns dias depois, uma nova linha, em verniz transparente, surge ao lado da primeira, deixando uma marca escura no mesmo chão. Por estabelecerem um diálogo com o desenho e a pintura, tais linhas despertaram meu interesse. Decido filmar cada linha separadamente e passo a tecer reflexões sobre os caminhos que a Arte percorre para se engendrar no mundo das coisas.

A referência imediata é a pintura dos Expressionistas Abstratos norte-americanos, movimento artístico amplamente difundido após a Segunda Guerra Mundial. Desde o final dos anos 1930, quando Jackson Pollock passa a jogar tinta sobre a tela diretamente da lata, ou deixa que ela escorra do pincel, o modo de se compreender a pintura se transforma, trazendo para a cena a atitude do artista, o qual passa a ser visto como uma espécie de performer, revelador, no mundo das coisas visíveis, do registro do gesto e da potência da cor. Para as gerações surgidas depois dos Expressionistas Abstratos, a pintura havia adquirido uma nova escala, não mais relacionada ao alcance do pulso do pintor, mas ao movimento de seu corpo.

A mudança no modo de apreciação das pinturas de Pollock é potencializada através das fotografias e vídeos realizados por Hans Namuth, que transformam a persona do pintor em performer. Se nas décadas de 1930/1940, a pintura de Pollock se afirma na cena internacional, nos anos de 1950, tais imagens da ação do pintor, ao deslocar a atenção do resultado final da obra para o gesto constitutivo do processo pictórico, de certa forma, antecipam a notoriedade que envolveria Andy Warhol e os artistas das gerações posteriores.

A partir dos anos 1970, com o fortalecimento do movimento da contracultura, o grafitte e a pichação passam a ser reconhecidos como expressão de uma Arte popular, feita nas ruas, por pessoas que usam palavras ou desenhos para deixar registros de suas 
existências. Adotados por galerias e incorporados ao mercado de Arte, os grafiteiros passam a trabalhar por encomenda, potencializando a adequação da mercadoria ao consumo capitalista. Perdem, na consagração de sua Arte, uma suposta pureza de ideias e princípios, mesmo quando observados como sintomas de uma civilização em desequilíbrio econômico e social. Muralistas por excelência, os grafiteiros disputam notoriedade com astros da música ou do futebol.

A tinta no chão da ciclovia, no entanto, me faz pensar, além da Action Painting pollockiana, em uma obra de Arte destituída de ambições que não seja a de sua própria existência, destinada a despertar no observador o estranhamento que pode dar início à percepção estética. Ou, o que me parece improvável, mas ainda assim divertido, pode ser apenas uma tinta que escorreu da lata furada enquanto um distraído pintor caminhava. Opto por considerá-la uma obra de Arte e a trato como tal. Tranquilizo-me ao lembrar que esta não seria a primeira querela acerca da definição do que é Arte, pois desde os ready-mades de Marcel Duchamp, as certezas no campo das Artes Visuais foram estilhaçadas.

No panorama da Arte Conceitual, os exercícios filosóficos engendram sentidos e a definição de Arte se torna mais complexa. Encontrada ao acaso, a linha de tinta na ciclovia, pode ser relacionada, mesmo que de modo invertido, ao objet trouvé duchampiano. Ao invés de estar diante de um objeto não artístico, ao qual se atribui a qualis de Arte quando transposto para espaços consagrados, estou diante de uma obra de Arte encontrada ao acaso e fora de um ambiente oficial; criada para questionar a própria qualis de arte.

Passado o primeiro impacto, realizo outras filmagens com maior atenção no desenho da linha e no sentido da caminhada, pequenos vídeos (Figuras 1 e 2) que, ao serem vistos por minha neta enquanto brincava com meu celular, geram a seguinte indagação: por que um vídeo segue a linha branca e outro a preta? 


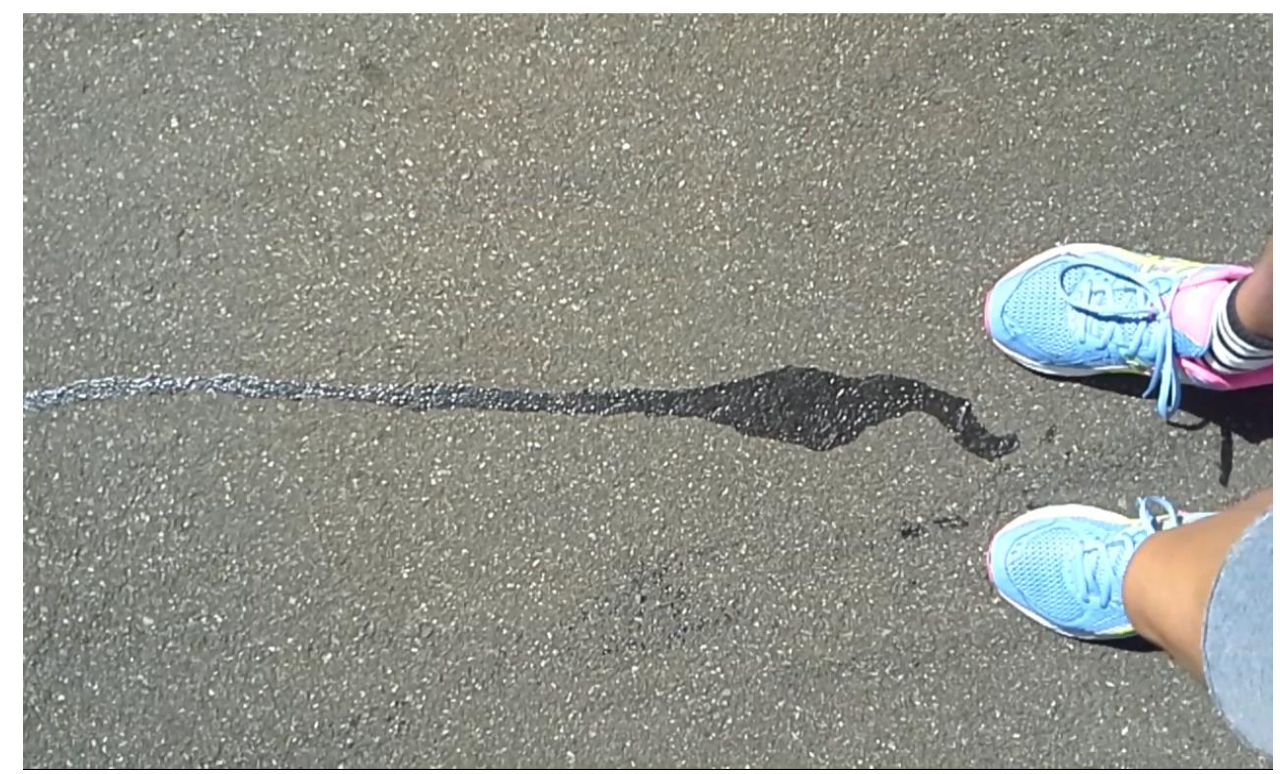

Figura 01. Frame do vídeo com película preta no asfalto

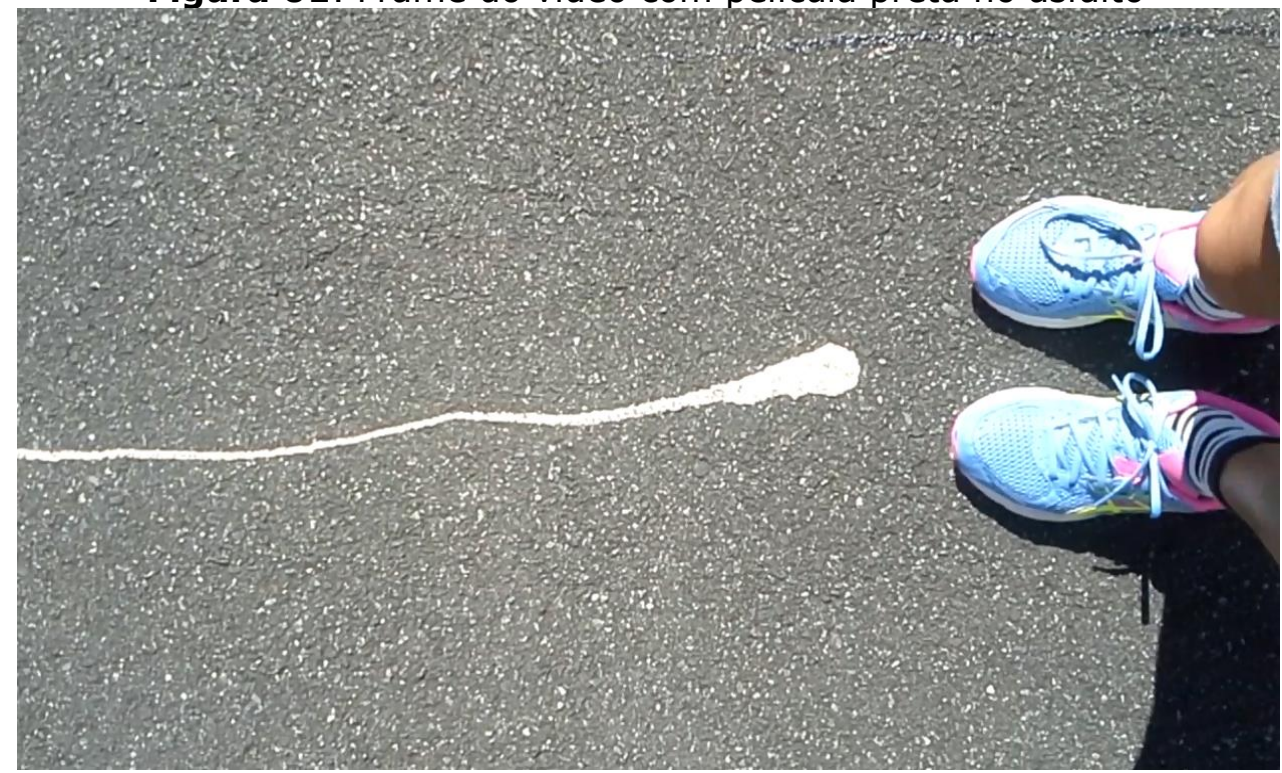

Figura 02. Frame do vídeo com a linha branca no asfalto

Dias depois, recebo por whatsup um vídeo feito por Maria Eduarda (Figura 3), mostrando que, na cidade onde mora, havia encontrado um lugar onde branco e preto estão juntos. Percebo que os filmes com as linhas adquirem outro sentido ao despertar o interesse de uma criança de quatro anos e instaurar com a avó um diálogo imagético, um tipo de comunicação não menos importante que a verbal. Decido fazer um vídeo reunindo fragmentos dos três planos gravados no celular: dois meus e um da Duda. 


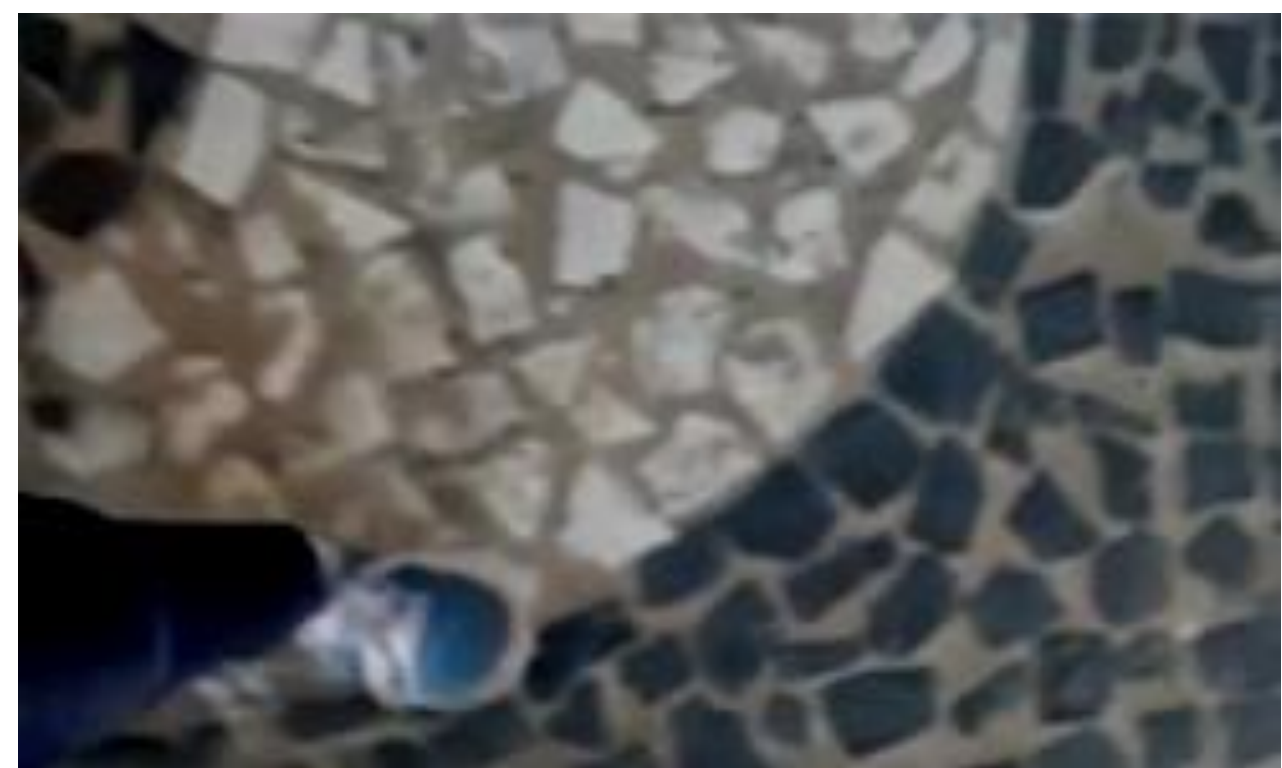

Figura 03. Frame do vídeo de Maria Eduarda

Das relações anteriormente estabelecidas com a pintura de Pollock, parto para outra referência importante para a minha formação enquanto artista e professora. A obra/processo Caminhando, de Lygia Clark, é uma prática que adoto em aulas desde a década de 1980. Monta-se uma fita de Moebius em papel, com a tesoura produz-se um corte na fita e percorre-se um caminho sempre avante (Figura 4). Acredito não conhecer outro processo artístico cuja capacidade de introspecção e revelação de percepções possa ser mais eficaz. A experiência proposta pela artista carioca em 1964 é uma maneira de resgatar processos que correlacionam os mundos interno e externo, reintegrando o imaginário na realidade humana. Nesta experiência, mesmo ao seguir adiante se retorna para trás.

Na tentativa de estabelecer possíveis relações entre Caminhando e Vídeo Encruzilhada, enfatizo que a obra proposta por Lygia Clark resulta numa experiência que, ao final, se aproxima de possibilidade de separação entre corpo e espírito, numa espécie de visualização de um estar fora do corpo, encarnação projetada no emaranhado de linhas dos restos de Caminhando. 


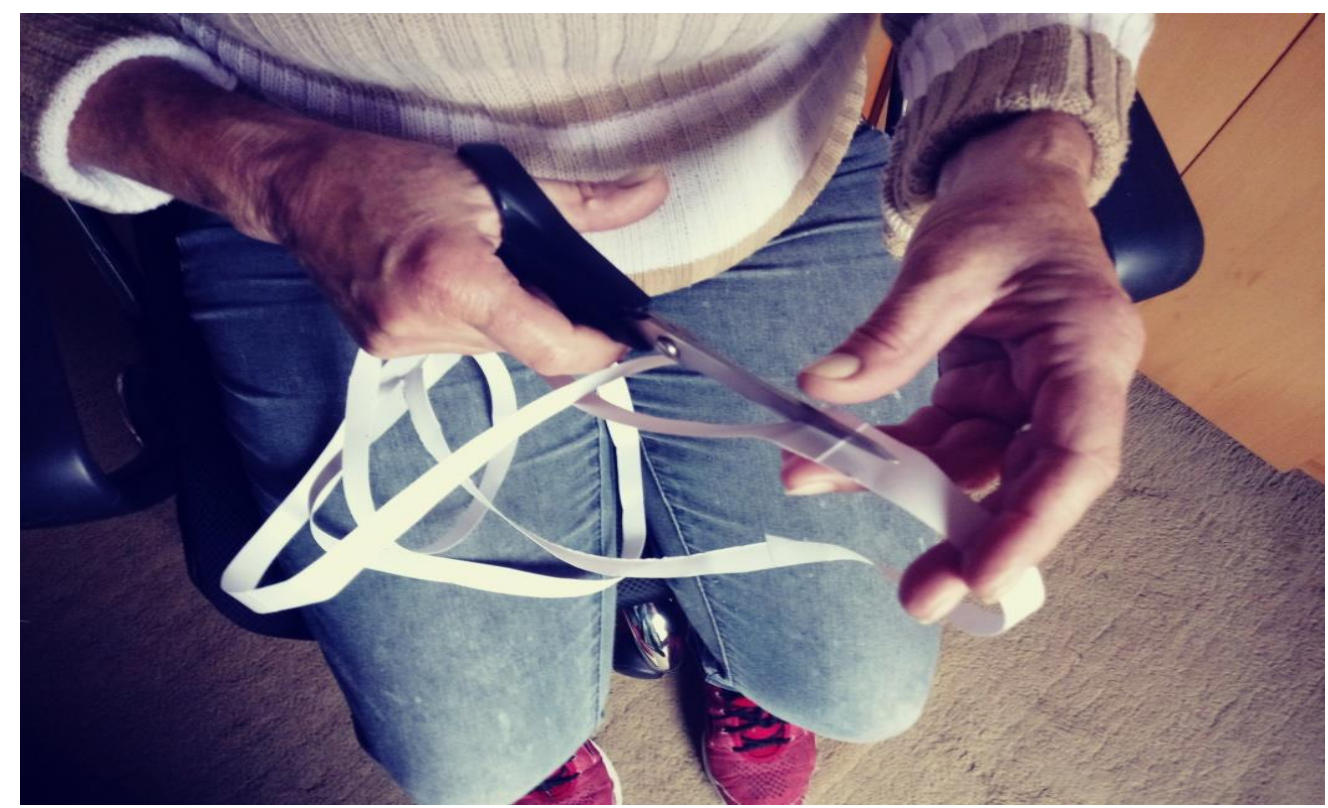

Figura 04. Reprodução do processo Caminhando

Para a artista, a ação do Caminhando é um empreendimento que permite a transformação do virtual em concreto: "A obra é o seu ato. À medida em que (sic) se corta a fita, ela se afina e se desdobra em entrelaçamentos. No fim o caminho é tão estreito que não pode mais ser aberto. É o fim do trabalho" (CLARK, 1964, p. 2).

Se Caminhando de Lygia Clark sugere percorrer um trajeto até não haver mais espaços possíveis de seguir adiante com a fita de Moebius, pensei em criar uma espécie de motocontínuo com o caminhar na ciclovia, tentativa que abandonei durante a edição, pois surgiram outros fatores, como a parada da câmera, que interessaram a mim e ao editor. A ideia de parceria me interessa mais do que a direta determinação do tipo de imagem que desejo alcançar e as contribuições de Neto foram elementos que procurei respeitar, deixando, inclusive, a trilha sonora a seu encargo, já que a música é a área em que tem atuado com maior afinco.

O que me interessa, naquele momento, é reunir as caminhadas, e mostrá-las em diversos sentidos, como se todo caminhar nos conduzisse a encruzilhadas. Afinal de contas, quando se caminha, tem-se que prestar atenção ao movimento das ruas transversais, cujo trânsito exige uma parada para observação. Eu não desejava, contudo, que outros elementos, tais como carros ou edifícios entrassem na obra. As linhas de tinta, meu caminhar, o caminhar da Duda e o olhar de Pedro Neto, me parecem elementos mais do que suficientes para o estabelecimento de uma narrativa artística.

A encruzilhada é um lugar de passagem e de encontro. Seu estudo me é familiar, pois em pesquisas anteriores, discorri sobre a imagem da encruzilhada a integrar os 
processos criativos de Paulo Leminski. Entre a produção de romances, poemas, músicas populares e tantas outras manifestações que compõem a vida do artista, as encruzilhadas representam a possibilidade de percorrer inúmeros caminhos e costumam apresentar enigmas a serem desvendados. Na maior parte das vezes, contudo, evidenciam caminhos que jamais serão percorridos, pois a escolha de um, implica o abandono de outros. Os possíveis critérios de seleção, numa encruzilhada, representam o mesmo tempo o ganho e a perda de possibilidades. E tais entrecruzamentos, acabam por formar o mote de Vídeo-Encruzilhada (Figura 5).

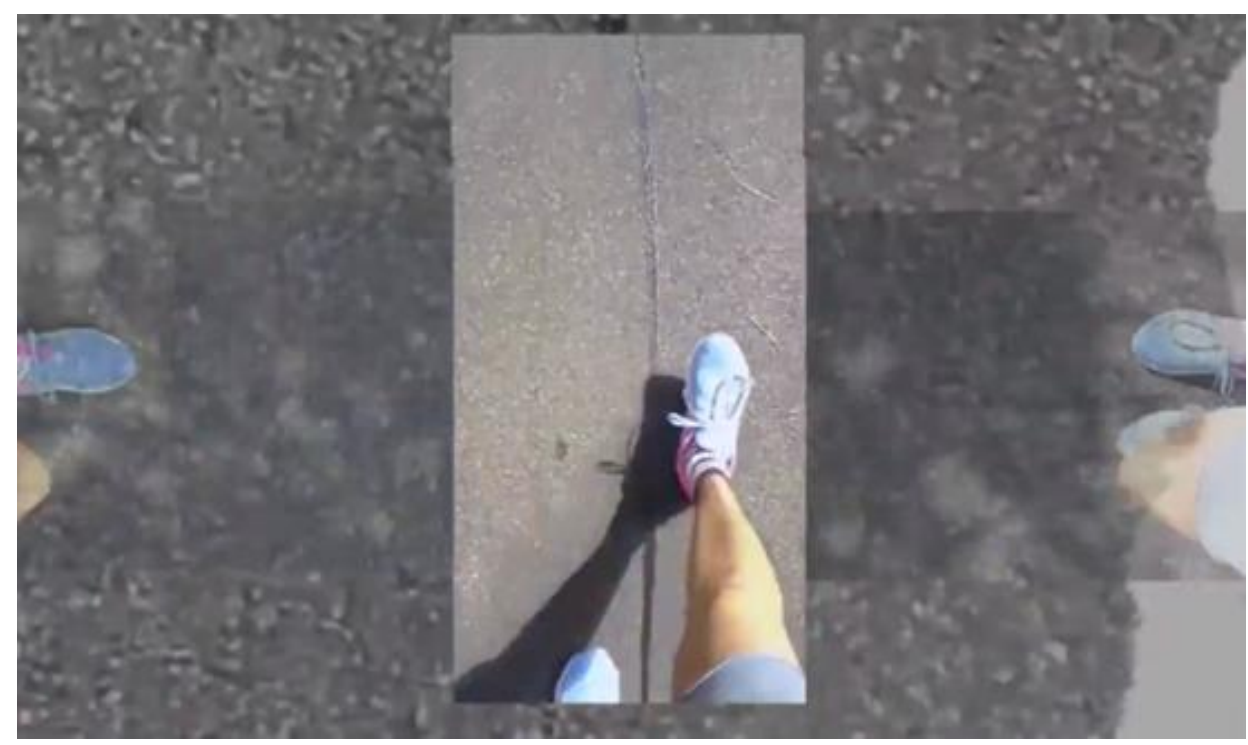

Figura 5. Frame de Vídeo-Encruzilhada

As sobreposições criadas com a fragmentação de meu próprio caminhar, através de cortes e de repetições das imagens em movimento evidenciam uma espécie de tenacidade vã, de teimosia em tentar compreender o incompreensível: esse vai e vem cotidiano cujo coroamento acontece com a morte, com o final da caminhada. As analogias entre caminhar e viver são inúmeras, e nelas as encruzilhadas aparecem como lugar onde dificuldades têm início ou fim. Em termos de desenho, a linha vertical que atravessa a horizontal, ou vice-versa, gera um ponto, centro do eixo ortogonal cartesiano, sobre o qual se debruçam os estudos da geometria. Localização, possibilidade de trajetórias e centralização são elementos que colocam em pauta a ideia de lugar, de presença e de pertencimento. Encruzilhadas que se movimentam em vários sentidos quebram a estabilidade, eliminam o ponto fixo que poderia estruturar um raciocínio 
lógico, numa espécie de deriva, de processos de terrritorialização e desterritorialização que caracterizam a contemporaneidade ${ }^{2}$.

\section{Considerações finais}

Acredito que a maneira com que introduzi o valor da Arte-Educação, no que concerne à sensibilização dos estudantes, tenha sido suficiente para explicitar a necessidade de sua presença nos currículos escolares, pois a abordagem reflexiva tem por objetivo educar sujeitos com autonomia de ideias e pensamentos. No que tange à educação superior, penso também que evidenciei com clareza a importância do professor/pesquisador nas universidades, mesmo que os tempos não pareçam muito propícios para as ações questionadoras como as que costumam ser levantadas no âmbito da produção artística.

A obra Vídeo-Encruzilhada, trabalho que norteia o artigo, foi correlacionada ao gesto pictórico de Jackson Pollock e ao Caminhando de Lygia Clark, não para tentar atribuir valor ao trabalho, mas para esclarecer, no primeiro caso, as razões do interesse pelas linhas de tinta e no segundo, a admiração por um trabalho processual que transforma a percepção acerca da experiência estética.

Questões como anonimato, trabalho coletivo e afeto são as marcas do vídeo, que ao criar encruzilhadas com o caminhar na ciclovia, mostram não apenas o movimento no espaço, mas introduzem cortes e sobreposições, na tentativa de expressar a possibilidade de estilhaçar o tempo, reflexo das conquistas do cinema e das novas tecnologias. Numa espécie de caminhar centrípeto, criam-se abismos visuais, pontes de significado que jamais completam seu sentido. Na esfera da Arte, o inexplicável e o enigmático são elementos que interessam artistas e pesquisadores.

Dentre os problemas encontrados na pesquisa, destaco a pouca visualização que o vídeo tem no youtube, plataforma na qual significativa quantia de obras é publicada na contemporaneidade. Realço, todavia, que o trabalho de pesquisa não tinha por objetivo a ampla midiatização nas redes informacionais. O resultado esperado, do qual faz parte este artigo, é disponibilizar aos jovens pesquisadores uma maneira de esclarecer possíveis relações entre produção artística e textual, evidenciando a importância da pesquisa poética na prática docente, já que a metodologia de pesquisa nas Artes Visuais se difere das realizadas em outros campos.

Dois anos depois de iniciada a pesquisa, as linhas na ciclovia sofreram vários acréscimos de camadas de tinta. Vermelhos, amarelos e azuis passam a compor a superfície do

${ }^{2} \mathrm{Na}$ impossibilidade de aprofundar tais conceitos neste artigo, indico a leitura de Derrida, Deleuze e Guattari. 
asfalto, numa profusão de cores que indicam a passagem de outras pessoas com as quais compartilho a percepção da obra.

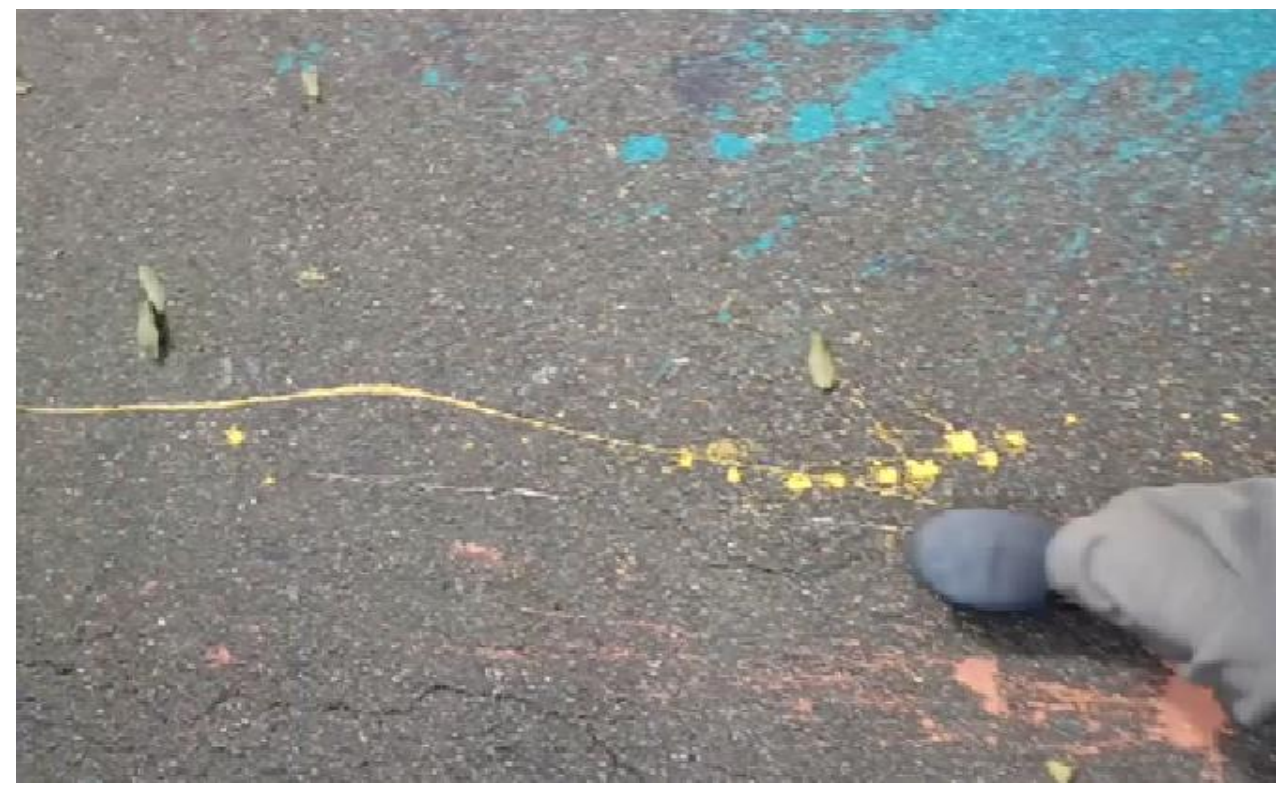

Figura 06. Imagem da ciclovia dois anos depois

Diante da banalização da obra de Arte em muitas esferas sociais e da sua evidente transformação em objeto de consumo pautado pelo valor de mercado, as linhas das quais me apropriei para a criação do vídeo, permanecem sendo alteradas e pelo que depreendi da observação de algumas pessoas que caminham na ciclovia, são consideradas fruto da ação de vândalos ou de pessoas que desconsideram o valor do patrimônio público.

Memória da pintura na desvalorização da representação mimética do mundo, os respingos de tinta guardam o registro de caminhantes anônimos, lembrando que a fruição artística não está reservada aos espaços oficiais de exibição de Arte, mas pode acontecer de forma despretensiosa e sutil. Mesmo para quem tal tipo de atividade pareça se aproximar da marginalidade, procuro lembrar que, na tentativa de resgatar emoções, de fazer reviver o sujeito sensível que habita cada um de nós, os artistas podem estar espreitando a vida cotidiana, procurando por brechas para engendrar sensibilidade no mundo. Compete também, ao Arte-Educador, investigar este tipo de produção que, longe do foco da atenção das mídias e do circuito oficial das Artes Visuais, se insere na vida sem outro objetivo que não seja o de ratificar a possibilidade de existência da Arte e de sua fruição. 
Continuo caminhando na ciclovia, ou pelo menos me esforçando para fazer exercícios aeróbicos, de acordo com recomendações da cardiologista. A novidade das manchas de tinta perdeu seu sentido e o acréscimo das demais camadas coloridas me fez sentir que os desdobramentos da obra não se esgotaram. Esta espécie de domínio público, onde qualquer pessoa pode fazer sua intervenção, continua me interessando e percebo que o vídeo que realizei nada mais é do que uma tentativa de dar visibilidade a um trabalho que me tocou profundamente, ou seja: busco contribuir para que a questão do anonimato seja ampliada e valorizada.

Percebo que, em sua formação, os estudantes muitas vezes almejam notoriedade e fama, acesso a galerias, participação em eventos importantes, etc. Longe de não levar tais eventos em consideração, gosto de saber que se reserva também um espaço para manifestações desinteressadas, nas quais o que se leva em conta é, acima de tudo, a possibilidade de estranhamento, de questionamento dos valores vigentes e da subversão a normas estabelecidas do consumo e da fruição artística.

Perder o fôlego, ou ter a respiração suspensa pela surpresa, são manifestações físicas que podem acompanhar a percepção estética. Tal tipo de emoção desinteressada se torna cada vez mais rara diante da qualidade das produções imagéticas ou audiovisuais atuais, criadas com o intuito de vender e consumir produtos. Resgatar tal tipo de sensibilidade, ou promover a reflexão acerca da viabilidade de sua existência, me parece ser uma das tarefas do professor/artista, quando o que se deseja é a formação de pessoas sensíveis, não apenas para a possível grandiosidade da obra de arte, mas também para sua singeleza.

\section{Referências}

CLARK, L. Caminhando. O mundo de Lygia Clark. 1964. Disponível em: <http://www.lygiaclark.org.br/arquivo_detPT.asp?idarquivo=17>. Acesso em: 7 set. 2017.

DUNNING, W. Roots of Postmodernism. Englewood Cliffs NJ: Prenctice-Hall, Inc., 1995.

FERVENZA, H. Olho mágico. In: BRITES, B.; TESSLER, E. (Orgs.). 0 meio como ponto zero: metodologia da pesquisa em artes visuais. Porto Alegre: UFRGS, 2002. p.65-76.

LEMINSKI, P. Catatau - um romance ideia. São Paulo: iluminuras, 2013.

MENDES, M. C. Vídeo-encruzilhada. Cor. 2:53min. Disponível em: <https://www.youtube.com/watch?v=I2KBOENjz_M>. Acesso em: 8 abri. 2018.

READ, H. A Educação pela Arte. São Paulo: Martins Fontes, 2013. 
TESSLER, E. Coloque o dedo na ferida aberta ou a pesquisa enquanto cicatriz. In: BRITES, B.; TESSLER, E. (orgs). O meio como ponto zero: metodologia da pesquisa em artes visuais. Porto Alegre: UFRGS, 2002. p.103-112.

${ }^{i}$ Professora Adjunta no Departamento de Artes da Universidade Estadual de Ponta Grossa / UEPG (2015). Doutorado em Comunicação e Linguagens / Universidade Tuiuti do Paraná (2014). Mestrado em Comunicação e Linguagens / Universidade Tuiuti do Paraná (2010). Especialização em História da Arte do Século XX / Escola de Música e Belas Artes do Paraná (2000). Graduação em Pintura - Bacharelado / Escola de Música e Belas Artes do Paraná (1984). Docente dos Cursos de Artes Visuais (2002 / 2015), Tecnologia em Fotografia (2008 / 2015) e Tecnologia em Design Gráfico (2014 / 2015) na Universidade Tuiuti do Paraná. Coordenadora do curso de pós graduação Lato Sensu Fotografia: Processos de Produção de Imagens / Universidade Tuiuti do Paraná (2012 / 2015). Coordena a pesquisa: Processos Poéticos em Artes Visuais: modos de articulação entre prática e teoria. Participa dos seguintes grupos de Pesquisa: Interart - interação entre arte, ciência e educação: diálogos e interfaces com as Artes Visuais; Uma reconstrução interdisciplinar do conhecimento a partir da criação de projetos referenciados nas relações Arte-Ciência do Renascimento pós-copernicano. Tem experiência na área de Artes Visuais, Educação e Comunicação / Cinema, atuando nos seguintes temas: Teorias e História da Arte e da Imagem (Pintura e Cinema) e Metodologia de Pesquisa.

Como citar esse artigo:

MENDES, Maria Cristina. Poéticas Visuais em Arte-Educação: Video-Encruzilhada. Revista Digital do LAV, Santa Maria: UFSM, v. 11, n. 3, p. 4-19, set./dez. 2018. 